\title{
Corporate Environmental Performance and Bank Credit Financing
}

\author{
Zhijian Liang ${ }^{1, *}$, Xueying Wang ${ }^{1}$ \\ ${ }^{1}$ Qinghai University, Xining, China
}

\begin{abstract}
Taking listed companies in heavy polluting industries in China from 2012 to 2018 as research samples, this paper examines the impact of corporate environmental performance on credit financing capacity. The results show that good environmental performance contributes to the improvement of corporate credit financing capacity, which is embodied in more new loans, lower loan rates, longer loan maturities, and less possibility of mortgage guarantee requirements.
\end{abstract}

\section{Introduction}

Environmental pollution, resource depletion, food safety and other problems are becoming more and more serious. As a result, the global awareness of environmental protection is gradually awakening. Environmental pollution control and ecological environmental protection have become the common demands of human society. As an important source of environmental pollution, industrial enterprises, especially heavy polluting enterprises, have attracted wide attention on environmental issues, and relevant academic research is also relatively adequate.

For example, according to the theory of resource and management efficiency and stakeholder theory, good environmental performance often represents the efficient use of resources and also wins the support of more stakeholders for the enterprise. For example, the popularization of the concept of environmental protection within the company is conducive to improving the working enthusiasm of employees ${ }^{[1]}$, and the accumulated "green reputation" can help the company win the support of consumers with environmental awareness, and realize the improvement of the company's production efficiency and expansion of revenue. The government attaches great importance to environmental issues and the promotion of officials depends on regional ecological and environmental performance, making it easier for enterprises with good environmental performance to establish contact with government officials and reduce the possibility of environmental administrative punishment ${ }^{[2]}$.

At the same time, companies bring environmental problems of credit risk and the implementation of green credit policy makes the corporate environmental information in the commercial Banks for loans exist demand, loan companies actively to carry on the environmental information disclosure, especially the high quality of environmental information disclosure, which reduces the information asymmetry between commercial Banks and, improve the ability of corporate credit financing. Relevant literature also supports this point of view. For example, Meng et al. (2014) ${ }^{[3]}$ found that enterprises with excellent environmental performance are more willing to disclose verifiable and quantitative "hard information" to show their efforts on environmental issues. Meanwhile, from the perspective of ethics, enterprises with good environmental performance or active fulfillment of social obligations tend to pay more attention to social morality ${ }^{[4]}$, showing less opportunism and higher degree of honesty ${ }^{[5]}$. Therefore, good environmental performance can help reduce the risk of corporate debt default and improve corporate credit financing ability, no matter in terms of illegal cost, performance improvement, information disclosure or ethics.

Therefore, based on the above analysis, the main research hypothesis of this paper is put forward.

hypothesis 1. Good environmental performance helps to improve the credit financing ability of enterprises.

\section{Sample selection and research design}

\subsection{Sample selection and data sources}

The research samples in this paper are listed companies in heavy pollution industries in Shanghai and Shenzhen stock exchanges from 2012 to 2018. The definition of heavy polluting industries refers to the Listed Companies Environmental Protection Inspection Industry Classification Management Catalogue issued by the Ministry of Ecology and Environment (formerly the Ministry of Environmental Protection) and the Listed Companies Industry Classification Guidelines issued by the China Securities Regulatory Commission. The emission fees of sample companies were collected manually from the annual report of the company, and other financial data were collected from the CSMAR database. Using this information, this paper can investigate the impact of corporate environmental performance on credit

"Corresponding author: liangzhijian1026@qq.com 
financing ability from the perspectives of new loans, loan interest rates, loan terms and credit loans. For the initial data, this paper carried out the following processing: (1) Excluded the ST companies with abnormal financial status; (2) eliminated companies with missing financial data; (3) $1 \%$ winsorize processed for all continuous variables. Finally, 885 sample observations were obtained.

\subsection{Variables and models}

In order to verify Hypothesis 1 of this paper, that is, good environmental performance contributes to the improvement of enterprise credit financing ability, this paper constructs the following OLS regression model (1):

$$
\begin{array}{r}
\text { Ability }=\beta_{0}+\beta_{1} C E P+\beta_{2} \text { Controls }+ \\
I N D+Y E A R+\varepsilon
\end{array}
$$

In Model (1), Ability refers to the credit financing Ability of an enterprise. Referred to previous literature, this paper measures the credit lending Ability of an enterprise from the following four aspects :(1) Loan, which is equal to the ratio of the new Loan of an enterprise to its total assets in the current year; (2) Rate, which is equal to the ratio of the interest expense in the financial expense to the total loan; (3) Term, which is equal to the ratio of long-term borrowings to total borrowings; (4) Credit, which is equal to the ratio of the amount of corporate Credit loans to the total borrowings. For the core explanatory variable, CEP (corporate environmental performance) is measured by referring to. The pollutant discharge rate is equal to the ratio of pollutant discharge fee and main business income (unit: 100 yuan). The higher the pollutant discharge rate, the better the enterprise's environmental performance.

For the selection of control variables, by referring to existing literature, other variables that may affect enterprise credit financing ability are included in the model: (1) Size, which is equal to the natural logarithm of the total assets of the enterprise at the end of the year; (2) Lev, which is equal to the ratio of the company's total liabilities and total assets at the end of the year; (3) Roe, which is equal to the ratio of the company's net profit after tax of the current year to its net assets at the end of the year; (4) Fixassets, which is equal to the ratio of the company's net tangible assets at the end of the year to its total assets at the end of the year; (5) Duality, If the chairman concurrently holds the position of general manager, the value is 1 ; otherwise, the value is 0 ; (6) State, When the ultimate controller is state-owned, State $=1$, otherwise State=0; (7) Top1, namely the shareholding ratio of the largest shareholder, is equal to the ratio of the number of shares held by the largest shareholder to the total number of shares of the company; In addition, industry fixed effect and annual fixed effect are also controlled in the model.

\section{Empirical results}

\subsection{Descriptive statistics}

Table 1 is a descriptive analysis of the main variables in this paper. As can be seen from Table 1, the mean and median of new Loan are $-0.9 \%$ and $-0.6 \%$ respectively, indicating that the proportion of bank Loan in total assets of sample enterprises are basically stable, and its standard deviation is 0.076 , indicating that different enterprises have great differences in their ability to obtain new Loan. The average loan Rate is 0.069 , indicating that the average annual interest Rate of loans obtained by sample enterprises is $6.9 \%$. The average values of loan term and credit are 0.285 and 0.472 respectively, indicating that the long-term borrowing of sample enterprises accounts for about $28.5 \%$ of the total borrowing, and the credit borrowing accounts for about $47.2 \%$ of the total borrowing. The mean and standard deviation of corporate environmental performance (CEP) are 0.186 and 0.272 respectively, indicating that the pollutant discharge fee of enterprises is 0.186 yuan per 100 yuan of main business income, and there is a big difference between different enterprises.

Table 1. Descriptive statistics of main variables

\begin{tabular}{lllllll}
\hline & Obs & Mean & Std. Dev. & Min & Median & Max \\
\hline Loan & 885 & -0.009 & 0.076 & -0.515 & -0.006 & 0.41 \\
Rate & 866 & 0.069 & 0.04 & 0.01 & 0.061 & 0.378 \\
Term & 636 & 0.285 & 0.217 & 0.003 & 0.236 & 1 \\
Credit & 684 & 0.472 & 0.324 & -0.009 & 0.450 & 1 \\
CEP & 885 & 0.186 & 0.272 & 0 & 0.097 & 2.022 \\
Size & 885 & 22.765 & 1.169 & 20.029 & 22.645 & 25.971 \\
Lev & 885 & 0.507 & 0.178 & 0.099 & 0.517 & 0.921 \\
Roe & 885 & 0.054 & 0.111 & -0.553 & 0.048 & 0.466 \\
Cash & 885 & 0.059 & 0.059 & -0.118 & 0.057 & 0.249 \\
FixAssets & 885 & 0.378 & 0.185 & -0.033 & 0.35 & 0.867 \\
State & 885 & 0.574 & 0.495 & 0 & 1 & 1 \\
Duality & 885 & 0.168 & 0.374 & 0 & 0 & 1 \\
Top1 & 885 & 0.367 & 0.148 & 0.084 & 0.359 & 0.789 \\
\hline
\end{tabular}




\subsection{Regression results}

Table 2 reports the empirical test results of the main research hypothesis in this paper, that is, the impact of corporate environmental performance on credit financing capacity. The explained variables in column (1) - column (4) are respectively new Loan, Loan interest Rate, Loan Term and Credit. The regression results show that corporate environmental performance (CEP) has a significant impact on credit financing ability. When the explained variable is Rate, the estimated coefficient of corporate environmental performance (CEP) is significantly negative, indicating that the better the enterprise environmental performance, the lower the bank loan interest rate. When the explained variables are Loan, Term and Credit, the estimated coefficient of CEP is significantly positive, indicating that good environmental performance is helpful for enterprises to obtain more new loans, longer loan term and weaker guarantee requirements. The above results support the main hypothesis of this paper that good environmental performance contributes to the improvement of corporate credit financing capacity.

Table 2. Corporate environmental performance and credit financing capacity

\begin{tabular}{lllll}
\hline & $(1)$ & $(2)$ & $(3)$ & $(4)$ \\
& Loan & Rate & Term & Credit \\
\hline CEP & $0.019^{* *}$ & $-0.011^{* * *}$ & $0.159^{* * *}$ & $0.098^{* *}$ \\
& $(2.246)$ & $(-3.073)$ & $(4.511)$ & $(2.049)$ \\
& & & \\
Controls & yes & yes & yes & yes \\
Constant & -0.049 & $0.208^{* * *}$ & 0.246 & 0.186 \\
& $(-0.790)$ & $(5.415)$ & $(1.197)$ & $(0.590)$ \\
\hline Year & yes & yes & yes & yes \\
Industry & yes & 866 & 636 & yes \\
Obs & 885 & 0.106 & 0.360 & 684 \\
Adj- $R^{2}$ & 0.156 & 0.260 \\
\hline$(1)$ The values of robust T are shown in brackets; $(2) * * *, * * *$ represent significant at the level of $1 \%, 5 \%$ and $10 \%$, respectively.
\end{tabular}

\subsection{Heterogeneity Test}

Analysis of heterogeneity of marketization degree in the region where the enterprise is located. Existing studies have also found that corporate credit financing is affected by market environment factors such as the financial development level of the region where the enterprise is located and the intervention degree of local government. Therefore, this paper takes the median of marketization level of 31 provincial administrative regions as the boundary, divides the samples into high-market subsamples and low-market subsamples, and regress Model (1) to investigate the impact of marketization level in the region of an enterprise on the relationship between enterprise environmental performance and credit financing ability. Specifically, if the marketization degree of the region where the sample company is located is less than the median of marketization level of each province, it will fall into the low-marketization subsample; otherwise, it will enter the high-marketization subsample. The marketization level of each province was determined by reference to NERI INDEX of Marketization of China' Provinces 2018 Report compiled by Fan Gang et al. As can be seen from Table 3, the regression results of the high-market subsample are consistent with those of the full sample, that is, corporate environmental performance (CEP) has positive relationship with Loan, Term and Credit, and the estimated coefficient of Rate is negative. The results of low market subsample regression show that CEP has no significant influence on the Loan, Rate, Term and Credit. This heterogeneity may be caused by the obvious professional advantages and economies of scale of commercial banks in high-market areas compared with low-market areas. In high-marketization areas, commercial banks can also more easily understand the qualifications and information of lending enterprises, and have sufficient attention to the potential environmental risks of lender. But more importantly, commercial banks can make credit decisions by the principle of economic efficiency and avoid the interference of local government. 
Table 3. Marketization, corporate environmental performance and credit financing ability

Panel A: high-market subsample

\begin{tabular}{lllll}
\hline & $(1)$ & $(2)$ & $(3)$ & $(4)$ \\
& Loan & Rate & Term & Credit \\
\hline CEP & $0.021^{* *}$ & $-0.015^{* * *}$ & $0.165^{* * *}$ & $0.141^{* * *}$ \\
& $(2.224)$ & $(-3.484)$ & $(3.665)$ & $(2.718)$ \\
Controls & & & \\
Constant & yes & yes & yes & yes \\
& -0.061 & $0.256^{* * *}$ & 0.021 & -0.451 \\
\hline Year & $(-0.790)$ & $(5.127)$ & $(0.074)$ & $(-1.201)$ \\
Industry & yes & yes & yes & yes \\
Obs & yes & yes & yes & yes \\
Adj- $R^{2}$ & 590 & 578 & 397 & 442 \\
\hline
\end{tabular}

Panel B: low-market subsample

\begin{tabular}{lllll}
\hline & $(1)$ & $(2)$ & $(3)$ & $(4)$ \\
& Loan & Rate & Term & Credit \\
\hline CEP & 0.005 & -0.013 & 0.056 & 0.018 \\
& $(0.157)$ & $(-1.274)$ & $(0.681)$ & $(0.191)$ \\
Controls & & & \\
Constant & yes & yes & yes & yes \\
& -0.157 & $0.203^{* * *}$ & 0.171 & $2.290^{* * *}$ \\
\hline Year & $(-1.171)$ & $(2.946)$ & $(0.435)$ & $(3.074)$ \\
Industry & yes & yes & yes & yes \\
Obs & yes & yes & yes & yes \\
Adj- $R^{2}$ & 295 & 288 & 239 & 242 \\
\hline
\end{tabular}

Note :(1) The values of robust $\mathrm{T}$ are shown in brackets; $(2) * * *, * *,{ }^{*}$ represent significant at the level of $1 \%, 5 \%$ and $10 \%$, respectively

\section{Conclusion}

Taking A-share listed companies in heavy polluting industries on the Shanghai and Shenzhen stock exchanges from 2012 to 2018 as research samples, this paper examines the impact of corporate environmental performance on credit financing capacity. The results show that good environmental performance contributes to the improvement of corporate credit financing capacity, which is embodied in more new loans, lower loan interest rates, longer loan terms and weaker guarantee requirements. Based on the research conclusions, this paper proposes the following policy recommendations: (1) Polluting enterprises should pay enough attention to their own environmental performance to avoid the impact of environmental problems on their business development; (2) Government should continue to give full play to the positive role of green finance in environmental governance, and provide important impetus for the comprehensive green transformation of the economy and society and the continuous improvement of the ecological environment.

\section{References}

1. Yadav PL, Han SH, Kim H. Sustaining Competitive Advantage Through Corporate Environmental Performance $[\mathrm{J}]$. Business Strategy and the Environment, 2017, 26(3): 345-357.

2. Du X, Weng J, Zeng Q, et al. Do Lenders Applaud Corporate Environmental Performance? Evidence From Chinese Private-owned Firms[J]. Journal of Business Ethics, 2017, 143(1): 179-207.

3. Meng X, Zeng S, Shi JJ, et al. The Relationship Between Corporate Environmental Performance and Environmental Disclosure: an Empirical Study in China[J]. Journal of Environmental Management, 2014, 145: 357-367.

4. Garriga E, Melé D. Corporate Social Responsibility Theories: Mapping the Territory[J]. Journal of Business Ethics, 2004, 53(1): 51-71.

5. Kim Y, Park MS, Wier B. Is Earnings Quality Associated with Corporate Social Responsibility? [J]. The Accounting Review, 2012, 87(3): 761-796. 